\title{
PSYCHOLOGICAL FACTORS AND CONSEQUENCES OF PSYCHOSOCIAL STRESS DURING THE PANDEMIC
}

DOI: 10.36740/WLek202109126

\author{
Natalya A. Maruta ${ }^{1}$, Marianna V. Markova ${ }^{2}$, Hanna M. Kozhyna ${ }^{3}$, Tetiana A. Aliieva ${ }^{2}$, Lyudmyla M. Yuryeva ${ }^{4}$, \\ Tsira B. Abdryakhimova ${ }^{5}$, Nataliia G. Pshuk ${ }^{6}$, Andrii M. Skrypnikov ${ }^{7}$ \\ 'STATE INSTITUTION “INSTITUTE OF NEUROLOGY, PSYCHIATRY AND NARCOLOGY OF THE NAMS OF UKRAINE”, KHARKIV, UKRAINE \\ 2KHARKIV MEDICAL ACADEMY OF POSTGRADUATE EDUCATION, KHARKIV, UKRAINE \\ ${ }^{3}$ KHARKIV NATIONAL MEDICAL UNIVERSITY, KHARKIV, UKRAINE \\ ${ }^{4}$ STATE INSTITUTION “DNIPROPETROVSK MEDICAL ACADEMY OF THE MINISTRY OF HEALTH OF UKRAINE”, DNIPRO, UKRAINE \\ ${ }^{5}$ BOGOMOLETS NATIONAL MEDICAL UNIVERSITY, KYIV, UKRAINE \\ ${ }^{6}$ NATIONAL PIROGOV MEMORIAL MEDICAL UNIVERSITY, VINNYTSIA, UKRAINE \\ ${ }^{7}$ POLTAVA STATE MEDICAL UNIVERSITY, POLTAVA, UKRAINE
}

\begin{abstract}
The aim: Study of psychological factors and consequences of psychosocial stress which is formed during the COVID-19 pandemic.

Materials and methods: In the research, we used methods: developed a common, assessment of psychosocial stress L. Reeder scale, assessment of distress R.Kessler, assessment of the presence of manifestations of anxiety-depressive response GAD-7, depression self-assessment scale PHQ-9, method of assessing neuropsychological adaptation I. Gurvich, assessment of psychosocial support D. Ziemet, the scale of assessment of family anxiety E. Eidemiller, W. Justickis, strategies for stress-coping behavior E. Heim, methods of assessing the quality of life A.A. Pushkarev, N.G. Arinchina (2000). The current factors of the impact of coronavirus on the mental state of the population have been investigated. The study involved 823 citizens of Ukraine, who filled out the developed Google form.

Results: Threats of coronavirus disease, violation of the usual life stereotype, restriction of leisure activity, harmful interest in news about the pandemic, usage of tobacco plays an important role in the mechanisms of distress formation. These conditions raise the risk of increased stress, anxiety and depression.

Conclusions: The investigations carried out suggested that the quarantine restrictions could be predisposing factors for mental health impairments. Under these conditions, risks of increased stress pressure, anxiety, and depression are rising.

Measures on psycho-prevention should be performed on the base of the regularities identified.
\end{abstract}

KEY WORDS: pandemic (COVID-19), psycho-emotional state, anxiety, stress, coping strategies, the quality of life.

Wiad Lek. 2021;74(9 p.l):2175-2181

\section{INTRODUCTION}

The 2019 coronavirus pandemic (COVID-19) has become a great challenge for people's mental health around the world.

High anxiety, depression, post-traumatic disorder and psychological distress rates are recorded among the nations during the pandemic [1-5].

Detection of the direct effect of COVID-19 on mental processes is a difficult problem, however, certain determinants identified in the conducted researches suggest the following [6]. Despite the undeniable need for isolation and physical distancing, which resist the high contagiousness and pathogenicity of the virus, those factors have a negative impact on mental health [7-10].

Research also notes the pathogenic role of psychosocial factors, including economic difficulties and financial loss (due to unemployment and declining incomes), school closures, lack of resources for health care, domestic violence and insufficient distribution of basic necessities.
Psychological consequences include fear of getting infected with COVID-19 and dying, loss of livelihood and loved ones, insecurity and anxiety about the future, social discrimination, separation from family and caretakers [11-14].

Common risk factors for mental disorders during the COVID-19 pandemic include women, the younger age group ( $\leq 40$ years), the presence of chronic / mental distresses, unemployment, students and frequent conversations via social media.

There is a higher prevalence of adverse psychological effects in the population compared to the spread of the pandemic [15-17].

Symptoms of adverse psychological consequences were more common at the onset of the outbreak, when people were subjected to mandatory quarantine, sudden unemployment, and the uncertainty associated with the COVID-19 outbreak [18]. 
The duration of mental symptoms should also be considered when assessing the psychological consequences of a coronavirus outbreak, as acute psychological responses to stressful or traumatic events have sometimes a protective and evolutionary nature [19-20].

Several prognostic factors have been identified in the course of research. Women were more vulnerable to developing symptoms of various forms of mental disorders during a pandemic, including depression, anxiety, post-traumatic stress disorder, and adaptation disorders [21-23]. High severity of psychological stress occurs in women because they make up a higher percentage of the workforce, which can be negatively affected by COVID-19, for example, in retail, services and health care.

People under the age of 40 also had more adverse psychological symptoms during a pandemic [24-25]. This conclusion may be partly related to their role in caring for families (ie, especially women) that provide financial and moral support to children or the elderly. Job losses and unpredictability, caused by the COVID-19 pandemy, among this age group can be particularly stressful. In addition, the majority of people under the age of 40 are students who may also experience stronger emotional upheavals due to school closures, cancellation of public events, lower learning efficiency in remote online courses and postponement of exams [24].

These data conform the results testifying that student status was associated with higher levels of depressive symptoms and post-traumatic stress symptoms during the COVID-19 outbreak [27].

People with chronic diseases (somatic / mental) developt more symptoms of anxiety and stress during COVID-19 pandemy [28-30].

Anxiety and worrying about coronavirus infection in patients with chronic diseases is partly due to their weakened immunity caused by pre-existing conditions, which makes them susceptible to infection and a higher risk of death. Significantly higher mortality rates have been reported in patients with diabetes, hypertension and coronary heart disease, but the exact causes remain unknown. In addition, another practical aspect of concern for patients with pre-existing conditions may be the delay and unavailability of medical services and treatment as a result of the COVID-19 pandemic. For example, because the rapidly growing number of patients with COVID-19 used hospital and medical resources, this could inadvertently affect the primary, secondary, and tertiary prevention of other diseases. Individuals with a history of mental disorders or current diagnoses of mental illness are also usually more sensitive to external stressors, such as the social isolation associated with a pandemic [31].

A few researches have found that frequent use of social networks / news related to COVID-19 caused symptoms of anxiety and stress [32].

Frequent use of social networks, the influence of potentially fakes, misinformation are the factors of increasing concern. Due to the unpredictable situation and a lot of unknown information about the new coronavirus, misinformation and fake news spread with ease through social networking platforms, creating unnecessary fears and concerns. Sadness and anxiety can also arise from the constant observation of members of a community suffering from a pandemic through social networking platforms or news reports [33].

\section{THE AIM}

The aim of our study was to identify the factors and psychological consequences of psychosocial stress, which is formed during the COVID-19 pandemic.

\section{MATERIALS AND METHODS}

In the study we used the following set of methods. We developed a common poll aimed at studying social demographic data, life conditions and-lifestyle during the quarantine, the presence of chronic diseases and psychodiagnostic techniques (assessment of psychosocial stress) (L. Reeder scale), assessment of distress (R. Kessler scale), assessment of the presence of manifestations of anxiety-depressive response (GAD-7), depression self-assessment scale (PHQ-9), method of assessing neuropsychological adaptation (I. Gurvich), assessment of psychosocial support (D. Ziemet), the scale of assessment of family anxiety (E. Eidemiller, W. Justickis), strategies for stress-coping behavior (E. Heim), methods of assessing the quality of life (AA Pushkarev, NG Arinchina, 2000), as well as mathematical methods of data processing.

The study involved 823 people who filled out a Google survey form.

\section{RESULTS}

The analysis of the socio-demographic condition of the respondents showed the following.

The vast majority of respondents lived in the city $88.21 \%$; $6.77 \%$ - in settlements; $5.35 \%$ - in urban settlements. Residents of 20 regions of Ukraine (Vinnytsia, Volyn, Dnipro, Donetsk, Zhytomyr, Zakarpattia, Zaporizhia, Ivano-Frankivsk, Kyiv, Krapivnitsky, Lviv, Mykolaiv, Odessa, Poltava, Rivne, Sumy, Ternopil, Kharkiv, Khmelnitsky, Kherson, Chernivtsi) took part in the survey. The most represented among the participants were respondents from Kharkiv (21.38\%), Dnipro (17.01\%), Lviv (16.77\%), Zaporizhia (10.08\%) and Poltava (8.74\%) areas.

The majority of the respondents were women (612 people, $74,36 \%$ ), men formed $25,64 \%$ (211 people). Analysis of the age characteristics of the respondents showed that the majority of respondents were under the age of $30-40.34 \%$ and aged $30-40-21.51 \%$. At the age of $45-50$ years there were $15.79 \%$ of respondents; at the age of $51-60$ years $12.27 \%$; at the age of more than 60 years $-10.00 \%$.

The marital status analysis showed that $47.51 \%$ were married, $43.5 \%$ - single, $8.99 \%$ - divorced. $51.03 \%$ of respondents did not have children; $23.57 \%$ had one child; $21.15 \%$ - two children; $4.25 \%-3$ and more children.

Analyzing the level of education, we noticed that $65.74 \%$ 

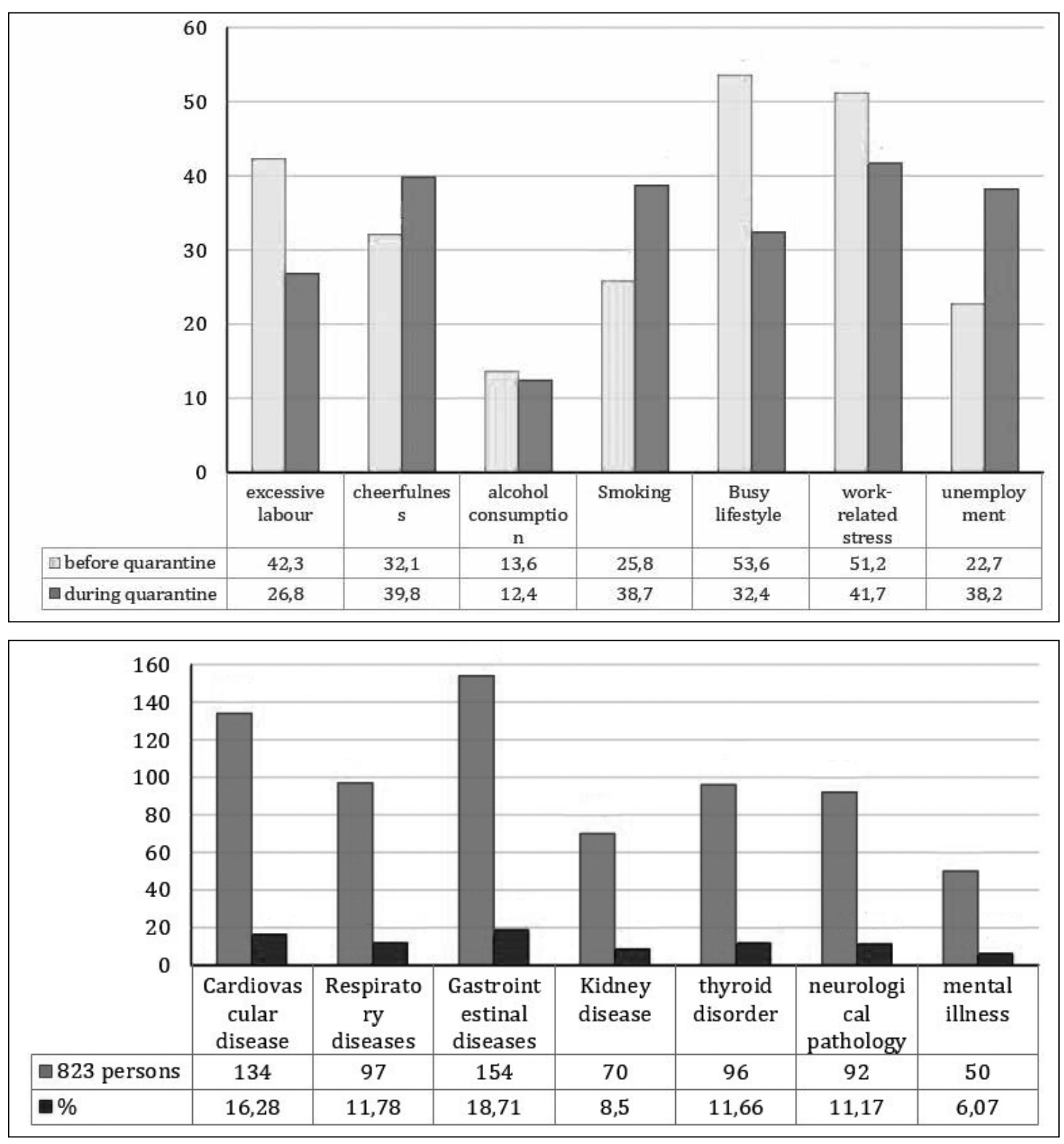

Fig. 1. Lifestyle in the group examined before and during quarantine.
Fig. 2. The presence of chronic diseases in the group of subjects of those surveyed had higher education; $12.76 \%$ - incomplete higher; $12.64 \%$ - average; $8.50 \%$ - special secondary; $0.36 \%$ - technical.

Living conditions in $56.62 \%$ were good; in $39.85 \%$ - satisfactory; in $3.52 \%$ - unsatisfactory.

In general, among the surveyed young people (up to 40 years old) predominated; female, childless; those with higher education and good living conditions.

During the study, we paid special attention to the analysis of living activity during the pandemic. The results showed that $60.14 \%$ of respondents comply with quarantine requirements and $39.86 \%$ - no. $24.54 \%$ continued to go to work during quarantine; $75.46 \%$ of respondents stayed at home (35.35\% continued to work remotely).

In $37.67 \%$ of those surveyed, the work was related to the possibility of infection with COVID-19, in $62.33 \%$ this possibility was not detected.

Respondents' assessments of their condition during quarantine were mixed. $74.24 \%$ of respondents believed that they would "survive"; $52.36 \%$ said they felt "not very well"; $30.86 \%$ reported that they felt "terrible, I can't stand the conditions of quarantine"; $17.25 \%$ reported the presence of a "feeling of loneliness."

At the same time, $20.53 \%$ of respondents rated their condition as "good, similar to being on vacation", and 17.49\% expressed a desire to "extend quarantine".

Studying the lifestyle before and during the quarantine period, it was found that the presence of excessive work before quarantine was found in $42.3 \%$, and in quarantine in $26.8 \%$ of respondents ( $\mathrm{p} \leq 0.05)$; lack of permanent work was registered in $22.7 \%$ and $38.2 \%$, respectively $(\mathrm{p} \leq 0.05)$ (Fig. 1).

Busy lifestyle was detected in $53.6 \%$ before and in 32.4\% during quarantine (at $\varphi_{\mathrm{emp}}=8.804 \varphi_{\mathrm{cr}}=2.31$, where $\mathrm{p} \leq 0.01) ; 51.2 \%$ - noted the presence of work stress before, and $41.7 \%$ - during quarantine (at $\varphi_{\mathrm{emp}}=3,875 \varphi_{\mathrm{cr}}=2,31$, where $\mathrm{p} \leq 0,01) ; 32.7 \%$ - found a state of vigor to, and $39.8 \%$ during quarantine (at $\varphi_{\mathrm{emp}}=3.367 \varphi_{\mathrm{cr}}=2.31$, where $\mathrm{p} \leq 0.01$ ). 
Summarizing the data obtained on the impact of quarantine on lifestyle, it should be noted that the number of overworked people in a stressful mode and in a hurry during quarantine decreased. One third of respondents (30.86\%) reported distress during quarantine. Under quarantine conditions, the number of people who do not have a permanent job has increased.

Analysis of the presence of chronic diseases showed that most often the respondents had diseases of the gastrointestinal tract (18.71\%), cardiovascular system (16.28\%), respiratory system $(11.78 \%)$, thyroid gland $(11.66 \%)$ and neurological diseases (11.17\%) (Fig. 2).

When studying the causes of anxiety (possible factors of mental trauma), the most important participants in the survey were selected:

- risk to life and health of relatives and friends (82.26\%);

- impossibility of a habitual way of life (travel, sports, visiting theaters, museums) $(79.82 \%)$;

- uncertainty in the actions of the authorities (79.10\%);

- restrictions on leisure outside the home $(74.11 \%)$;

- COVID-19 disease of family members, relatives, acquaintances (75.45\%);

- lack of special treatment for COVID-19 (71.08\%);

- the possibility of contracting a life-threatening disease (63.54\%);

- danger to one's own life (63.18\%).

Analyzing the presented data, it should be noted, that the vast majority of respondents were concerned about the risk to the life and health of loved ones, disruption of the usual way of life, restriction of leisure outside the home and uncertainty in the actions of the authorities.

Assessing the impact of news related to the COVID-19 pandemic, it was found that $44.85 \%$ of respondents considered it necessary to reduce the time spent searching for and reading such news; $17.25 \%$ felt guilty for searching and reading them; $25.15 \%$, on the other hand, wanted to search and read pandemic news.

Assessing the level of interest in information about COVID-19, $51.40 \%$ of respondents considered this level to be normative; $9.60 \%$ noted interest in this information; $16.4 \%$ risky interest, $22.60 \%$ - pathological (harmful) interest.

Analysis of alcohol consumption during quarantine showed that $13.24 \%$ of respondents had a feeling about the need to reduce alcohol consumption; $10.05 \%$ felt guilty about drinking alcohol; $8.75 \%$ were irritated when someone told them about the need to reduce alcohol consumption, $6.68 \%$ expressed a desire to drink alcohol, when they woke up.

Most of the respondents noted the absence of problems with alcohol (89.06\%); 4.50\% reported drinking alcohol; $2.67 \%$ - systematic alcohol consumption; $3.77 \%$ - alcohol dependence.

In the study of smoking, it was noted that tobacco use was registered in $22.60 \%$ of respondents. At the same time 9.11\% burned the first cigarette within the first 5 minutes after waking up, $15.43 \%$ could give up the first cigarette; $11.78 \%$ burned 10 or fewer cigarettes a day $(5.58 \%$ burned $11-20$ cigarettes; $2.79 \%$ burned $21-30$ cigarettes). $13.12 \%$ of respondents smoked more often in the early hours of the morning; 7.04\% reported continuing to smoke when ill. Assessment of the effects of smoking showed that tobacco dependence was not found in $40.80 \%$; weak or moderate tobacco dependence was registered in $44.62 \%$; strongly expressed dependence - in $14.52 \%$.

That is, when assessing the informational effects, the effects of alcohol and tobacco during quarantine, it should be noted the presence of harmful interest in news about the pandemic (22.6\%); low rates of systematic use (2.67\%) and alcohol dependence (3.77\%); high rates of weak and moderate dependence on tobacco $(44.62 \%)$, as well as strong dependence (14.52\%).

Alcohol before quarantine was consumed by $13.6 \%$ of respondents, during quarantine $-12.4 \%$; tobacco smoking was reported by $25.8 \%$ before and $38.7 \%$ during quarantine.

Given the huge role of social support in the genesis of social stress, we conducted a study of family anxiety. According to the results of such a study, it was found that $31.71 \%$ of respondents showed a sense of guilt, 59.41\% had a high level of anxiety, $62.21 \%$ had a high level of stress. A high overall rate of family anxiety was found in $68.53 \%$.

It should be noted that according to the multidimensional scale of perception of social support (MSPSS), the respondents showed a high level of this indicator in terms of support for family $(82.74 \%)$, friends $(82.50 \%)$, significant people $(70.23 \%)$ and overall indicator of the level of support (89.42\%).

Summarizing the data on the emotional load of the respondents, it should be noted that the vast majority of respondents felt anxiety of a minimal and moderate level; medium and high levels of anxiety were registered in $18.46 \mathrm{t} \%$ and $8.26 \%$, respectively. The indicators of the level of depression were similar: in the vast majority of respondents the level of depression was minimal, mild and moderate, severe and very severe depression was found in $11.91 \%$ and $5.22 \%$, respectively. Despite the high level of social support, $68.53 \%$ showed a high overall rate of family anxiety.

A study of the level of anxiety using GAD7 showed that the minimum anxiety was determined by $43.25 \%$, moderate $-30.01 \%$, medium $-18.46 \%$, high $-8.26 \%$.

Analyzing the level of depression, we noted that $36.21 \%$ had minimal depression, $30.01 \%$ - mild, $16.64 \%$ - moderate, $11.91 \%$ - severe, $5.22 \%$ - very severe.

Assessment of stress levels in a group of respondents according to the method of Kessler R.C. showed that most of the subjects had a low level of stress (80.19\%), 18.46\% an average level, $1.34 \%$ - a high level of stress.

Assessing the level of stress, anxiety and depression in the respondents, it should be noted that the average level of stress was $18.47 \%$, and high - in $1.34 \%$.

$18.47 \%$ had an average level of anxiety, and $8.26 \%-$ high. Severe depression was determined by $11.91 \%$, very severe $-5.22 \%$.

Respondents' quality of life was assessed in terms of physical health, emotional state, social and cognitive functions. 
Table I. Quality of life assessment

\begin{tabular}{|c|c|c|c|}
\hline & \multicolumn{2}{|c|}{823 people } & \multirow{2}{*}{$\begin{array}{c}\mathbf{M} \pm \mathbf{m} \\
\text { average value }\end{array}$} \\
\hline & absolute number & $\%$ & \\
\hline \multicolumn{4}{|c|}{ Physical mobility } \\
\hline low level (10-30 point) & 67 & 8,14 & \multirow{3}{*}{$69,5 \pm 2,51$} \\
\hline average level (35-65 point) & 288 & 34,99 & \\
\hline high level (65-100 point) & 468 & 56,87 & \\
\hline \multicolumn{3}{|c|}{ Emotional condition } & \\
\hline low level (10-30 point) & 128 & 15,55 & \multirow{3}{*}{$72,39 \pm 3,27$} \\
\hline average level (35-65 point) & 336 & 40,83 & \\
\hline high level (65-100 point) & 359 & 43,62 & \\
\hline \multicolumn{3}{|c|}{ Social functions } & \\
\hline low level (10-30 point) & 84 & 10,21 & \multirow{3}{*}{$69,64 \pm 2,68$} \\
\hline average level (35-65 point) & 231 & 28,07 & \\
\hline high level (65-100 point) & 508 & 61,72 & \\
\hline \multicolumn{3}{|c|}{ Cognitive function } & \\
\hline low level (10-30 point) & 62 & 7,53 & \multirow{3}{*}{$96,05 \pm 3,24$} \\
\hline average level (35-65 point) & 204 & 24,79 & \\
\hline high level (65-100 point) & 557 & 67,68 & \\
\hline
\end{tabular}

The majority of respondents assessed their physical health at a high level $(56,87 \%), 34,99 \%$ - at the average level, only $8.14 \%$ is at the low level. At the same time, a quantitative analysis of the results on separate scales showed an increase in indicators that points at a deterioration in health during daily exercise (5.64 points) and a discrepancy between the state of Health and the desire to acquire a profitable job (5.77 points) (Table I).

The analysis of the emotional component of the respondents ' quality of life showed a predominance of high $(43.62 \%)$ and average $(40.83 \%)$ levels of the indicator. The presence of a low level was noted by $15.55 \%$ of respondents. The analysis of this indicator on the scales reflected high values on the scale of "I feel that no one cares about me" (5.65 points) and on the scale of "I feel oppressed and depressed " (5.32 points).

The study of social functions within the quality of life showed that $61.72 \%$ identified a high level of social activity, $28.07 \%$ - an average level, and $10.21 \%$ - a low level. Individual scales analysis showed high scores on the scales "my health condition interferes with normal vacation" (6.06 points).

During the studying of cognitive functions, it was found that $67.68 \%$ of the respondents noted the presence of a high level of cognitive functions, $24.79 \%$ - an average level; $7.53 \%$ - a low level. The highest scale in this section was "my health condition leads to financial problems" (6.04 points).

Summarizing the data obtained in this study, the following should be noted.

Socio-demographic characteristics of respondents (823 people) included the predominance of the female $(74.36 \%)$, age groups up to 40 years $(61.85 \%)$, city resi- dents (88.21\%), single and divorced (52.49\%), people with higher education (65.74\%), good and satisfactory living conditions (56.62\% and $39.85 \%$, respectively).

When studying the impact of quarantine restrictions on the lifestyle of respondents, it was found that the number of people working excessively in stressful and hasty mode during quarantine had decreased. At the same time, the number of people who do not have a permanent job has increased under quarantine conditions, $30.86 \%$ of those surveyed reported during quarantine.

Analysis of distress factors (causes of anxiety) showed that the overwhelming majority of respondents were worried under the influence of such factors as risk to the life and health of loved ones $(82.26 \%)$, violation of the usual lifestyle $(79.82 \%)$, uncertainty in the actions of the authorities $(79.10 \%)$, restriction of leisure time outside the home (74.11\%).

Assessing lifestyle changes during quarantine, it was detected that $22.6 \%$ of respondents noted a harmful interest in news about the pandemic; $44.62 \%$ - weak and moderate dependence on tobacco, low rates of systematic use and alcohol dependence (2.67\% and $3.77 \%$, respectively).

A study of stress, anxiety, and depression levels found that $18.47 \%$ had moderate stress levels and $1.3 \%$ had high levels. Moderate and high rates of anxiety and depression were recorded in $1 / 5-1 / 4$ of the respondents. $18.46 \%$ had an average level of anxiety, and $8.26 \%$ had a high level of anxiety. The severe level of depression was determined by $11.91 \%$, very high level by $5.22 \%$.

The analysis of examination of the quality of life has demonstrated, that $8.14 \%$ had a low level of its physical component, $15.55 \%$ had a low level of its emotional component, and $10.21 \%$ had a low level of a social activity. 


\section{DISCUSSION}

Summarizing the data obtained in this study, it should be noted that quarantine restrictions in some way affect the lifestyle of respondents.

It has been noted that during quarantine the number of people overworking in stress and haste mode is decreasing. At the same time, the number of people who have a permanent job is decreasing and the number of people who have distress during quarantine is increasing. The next pattern is the influence of distress factors, which manifested themselves in the form of concern for the lives and health of loved ones, concern for the violation of normal lifestyles, insecurity in actions of the authorities and restrictions on leisure outside. Also, we have found changes in lifestyle during quarantine, which manifested in the presence of harmful interest in the news and the presence of weak or moderate dependence, mainly on tobacco. Alcohol dependence in our study was less pronounced.

According to the results of the study of the level of stress, anxiety and depression, it has been found that the respondents have a medium and high level of anxiety and depression.

We obtained interesting data when assessing the quality of life of respondents. Despite the fact that the overall indicators of quality of life and performance in the physical, emotional, social and cognitive spheres were high, quantitative analysis of individual scales revealed the following negative trends. These are the deterioration of health during daily activities, the inconsistency of the state of health with the desire to get a well-paid job, feelings of loneliness and depression; impossibility to go on a good vacation and prevent financial problems due to the state of health. The data obtained in the study provide some prospects for psychoprophylaxis and psychoeducation among the population to strengthen the psychological state and mental health of the population.

\section{CONCLUSIONS}

Summarizing the data obtained in 823 examined patients during quarantine during the Covid-19 pandemic, we can describe the condition as follows:

1. The investigations carried out suggested that the quarantine restrictions could be predisposing factors for mental health impairments.

2. The threat of coronavirus disease, a disruption of a habitual life stereotype, leisure restrictions, a harmful interest in news about the pandemic, and tobacco abuse play an important role in mechanisms of distress formation.

3. Under these conditions, risks of increased stress pressure, anxiety, and depression are rising.

4. The analysis of examination of the quality of life has demonstrated, that $8.14 \%$ had a low level of its physical component, $15.55 \%$ had a low level of its emotional component, and $10.21 \%$ had a low level of a social activity.

5. Measures on psycho-prevention should be performed on the base of the regularities identified.

\section{REFERENCES}

1. Wang C., Pan R., Wan X., Tan Y., Xu L., Ho C.S., Ho R.C. Immediate psychological responses and associated factors during the initial stage of the 2019 coronavirus disease (COVID-19) epidemic among the general population in China. Int. J. Environ. Res. Public Health. 2020;17(5):1729. doi: 10.3390/ijerph17051729.

2. Wasserman D, van der Gaag R, Wise J. The term "physical distancing" is recommended rather than "social distancing" during the COVID-19 pandemic for reducing feelings of rejection among people with mental health problems. Eur Psychiatry. 2020;63:e52.

3. World Health Organization (WHO) [Internet], Coronavirus disease (COVID-2019) situation reports [cited 2020 Aug 15]. Available from: https://www.who.int/emergencies/diseases/novel-coronavirus-2019/ situation-reports.

4. World Health Organization (WHO) [Internet], Mental health and COVID-19 [cited 2020 Aug 15]. Available from: http://www.euro.who. int/en/health-topics/noncommunicable-diseases/mental-health/ data-and-resources/mental-health-and-covid-19.

5. World Health Organization (WHO) [Internet]. WHO briefing note Mental health and psychosocial considerations during COVID-19 outbreak [cited 2020 Aug 15], Available from: https://www.who. int/docs/default-source/coronaviruse/mental-health-considerations. pdf?sfvrsn $=6 \mathrm{~d} 3578 \mathrm{aM0}$.

6. Karpenko Olga A., Syunyakov TimurS., Kulygina Maya A., et al. Impact of COVID-19 pandemic on anxiety, depression and distress - online survey results amidthe pandemic in Russia. Consortium Psychiatricum. 2020; 1:8-20.

7. Hao F, Tan W, Jiang L, et al. Do psychiatric patients experience more psychiatric symptoms during COVID-19 pandemic and lockdown? A case-control study with service and research implications for immunopsychiatry. Brain Behav Immun. 2020;87:100-6.

8. Pfefferbaum B, North CS. Mental health and the Covid-19 pandemic. N Engl J Medicine. 2020;383:510-2.

9. Vindegaard N, Eriksen Benros M. COVID-19 pandemic and mental health consequences: systematic review of the current evidence. Brain Behav Immun. 2020;S0889-1591:30954-5.

10. Zhang SX, Wang Y, Rauch A, Wei F. Unprecedented disruption of lives and work: health, distress and life satisfaction of working adults in China one month into the COVID-19 outbreak. Psychiatry Res. 2020;288:112958.

11. Adhanom Ghebreyesus T. Addressing mental health needs: an integral part of COVID-19 response. World Psychiatry. 2020;19:129-30.

12. Gruber C. Impaired interferon signature in severe COVID-19. Nat Rev Immunol. 2020;20:353.

13. Unützer J, Kimmel RJ, Snowden M. Psychiatry in the age of COVID-19. World Psychiatry. 2020;19:130-1

14. Wright L, Steptoe A, Fancourt D. Are we all in this together? Longitudinal assessment of cumulative adversities by socioeconomic position in the first 3 weeks of lockdown in the UK. J Epidemiol Community Health.2020;74:683-8.

15. Huang Y. Prevalence of mental disorders in China: a cross-sectional epidemiological study. Lancet Psychiat. 2019;6(3):211-224. doi: 10.1016/S2215-0366(18)30511-X.

16. Lim G.Y., Tam W.W., Lu Y., et al. Prevalence of depression in the community from 30 countries between 1994 and 2014. Sci. Rep. 2018;8(1):2861. doi: 10.1038/s41598-018-21243-x.

17. Moghanibashi-Mansourieh A. Assessing the anxiety level of Iranian general population during COVID-19. Asian J. Psychiatr. 2020;51 doi: 10.1016/j.ajp.2020.102076. 
18. Ho C.S.H., Chee C.Y., Ho R.C.M. Mental health strategies to combat the psychological impact of coronavirus disease (COVID-19) beyond paranoia and panic. Ann. Acad. Med. Singapore. 2020;49(3):155-160.

19. Gilbert P. Evolution and depression: issues and implications. Psycho. Med. 2006;36(3):287-297. doi: 10.1017/S0033291705006112.

20. Yaribeygi H., Panahi Y., Sahraei H., et al. The impact of stress on body function: a review. EXCLI J. 2017;16:1057-1072. doi: 10.17179/ excli2017-480.

21. Ahmed M.Z., Ahmed 0., Zhou A., et al. Epidemic of COVID-19 in China and associated psychological problems. Asian J. Psychiatr. 2020;51 doi: 10.1016/j.ajp.2020.102092.

22. Gao J., Zheng P., Jia Y., et al. Mental health problems and social media exposure during COVID-19 outbreak. PLoS ONE. 2020;15(4) doi: 10.1371/ journal.pone.0231924.

23. Lei L., Huang X., Zhang S., et al. Comparison of prevalence and associated factors of anxiety and depression among people affected by versus people unaffected by quarantine during the covid-19 epidemic in southwestern China. Med. Sci. Monit. 2020;26 doi: 10.12659/ MSM.924609.

24. Cao W., Fang Z., Hou G., et al. The psychological impact of the COVID-19 epidemic on college students in China. Psychiatry Res. 2020;287 doi: 10.1016/j.psychres.2020.112934.

25. Huang Y., Zhao N. Generalized anxiety disorder, depressive symptoms and sleep quality during COVID-19 outbreak in China: a web-based cross-sectional survey. Psychiatry Res. 2020;288 doi: 10.1016/j. psychres.2020.112954.

26. Olagoke A.A., Olagoke 0.0., Hughes A.M. Exposure to coronavirus news on mainstream media: the role of risk perceptions and depression. $\mathrm{Br}$. J. Health Psychol. 2020 doi: 10.1111/bjhp.12427.

27. Samadarshi S.C.A., Sharma S., Bhatta J. An online survey of factors associated with self-perceived stress during the initial stage of the COVID-19 outbreak in Nepal. Ethiop. J. Health Dev. 2020;34(2):1-6.

28. Mazza C., Ricci E., Biondi S., et al. A nationwide survey of psychological distress among Italian people during the COVID-19 pandemic: immediate psychological responses and associated factors. Int. J. Environ. Res. Public Health. 2020;17:3165. doi: 10.3390/ijerph17093165.

29. Ozamiz-Etxebarria N., Dosil-Santamaria M., Picaza-Gorrochategui M.,et al. Stress, anxiety and depression levels in the initial stage of the COVID-19 outbreak in a population sample in the northern Spain. Cad. Saude. Publica. 2020;36(4) doi: 10.1590/0102-311X00054020.

30. Özdin S., Özdin S.B. Levels and predictors of anxiety, depression and health anxiety during COVID-19 pandemic in Turkish society: the importance of gender. Int. J. Soc. Psychiatry. 2020:1-8. doi: $10.1177 / 0020764020927051$.

31. LiZ. Vicarious traumatization in the general public, members, and nonmembers of medical teams aiding in COVID-19 control. Brain Behav. Immum. 2020 doi: 10.1016/j.bbi.2020.03.007.

32. Pierce M, McManus S, Jessop C, et al. Says who? The significance of sampling in mental health surveys during COVID-19. Lancet Psychiatry. 2020;7(7):567-8. Epub 2020/06/06. doi: 10.1016/s22150366(20)30237-6.
33. Erku D.A., Belachew S.W., Abrha S., et al. When fear and misinformation go viral: pharmacists' role in deterring medication misinformation during the'infodemic'surrounding COVID-19. Res. Social. Adm. Pharm. 2020. doi: 10.1016/j.sapharm.2020.04.032.

The research was carried out within the framework of the scientific research work of the Department of Psychotherapy of the Kharkiv Medical Academy of Postgraduate Education of the Ministry of Health of Ukraine on the topic "Mental health disorders under social stress: clinical phenomenology, predictors of formation, system of psychodiagnostics, psychotherapy and psychological rehabilitation" (state registration number 0120U101490).

\section{ORCID and contributionship:}

Natalya A. Maruta: 0000-0002-6619-9150 A,E,F

Marianna V. Markova: 0000-0003-0726-4925 B,D,F

Hanna M. Kozhyna: 0000-0002-2000-707X ${ }^{C, F}$

Tetiana A. Aliieva: 0000-0003-3511-027X ${ }^{B, F}$

Lyudmyla M. Yuryeva: 0000-0002-1713-1037 D,F

Tsira B. Abdryakhimova: 0000-0002-9406-2696 C,F

Nataliia G. Pshuk: 0000-0001-9857-2565 B,F

Andrii M. Skrypnikov: 0000-0002-1562-9421 E,F

\section{Conflict of interest:}

The Author declare no conflict of interest

\section{CORRESPONDING AUTHOR Natalya A. Maruta}

Department of Borderline Psychiatry of the

SI "Institute of Neurology, Psychiatry and

Narcology of the NAMS of Ukraine"

Akademika Pavlova Street, 46, Kharkiv, 61068, Ukraine

tel: +380577255813

e-mail:mscience@ukr.net

Received: 29.05 .2021

Accepted: 25.08 .2021

A - Work concept and design, B - Data collection and analysis, C - Responsibility for statistical analysis, D -Writing the article, $\mathbf{E}$-Critical review, $\mathbf{F}$ - Final approval of the article 